\title{
CARLOS MARTÍNEZ MORENO \\ TESTIGO DE CARGO
}

POR

HUGO FONTANA

Raigal, muchas veces excesivo (con lo que ello descuenta del resultado de una obra), Carlos Martínez Moreno fue el creador de una saga narrativa que encierra o envuelve los veinte años más conflictivos de la historia del siglo XX uruguayo.

Nacido en el departamento de Colonia en 1917, CMM se establece en su juventud en Montevideo, donde cursa estudios de Derecho y comienza a ejercer a poco de recibirse, agregando a su desempeño profesional una intensa actividad como editorialista y periodista cultural (la que no abordaremos en el presente trabajo), básicamente en el campo de la crítica cinematográfica, literaria y sobre todo teatral. A principios de la década del ' 40 da a conocer sus primeros cuentos. En 1956 con la nouvelle Cordelia obtiene el primer premio en un concurso convocado por la revista Número, y en 1958, con Los aborígenes, el segundo premio en el concurso literario de Life en español, participando luego en una antología que llevó como título Ceremonia secreta y otros cuentos de América Latina. Pero es recién en 1960, a los 43 años de edad, que reúne por primera vez seis relatos y los publica en libro: Los días por vivir. Seguramente, más de veinte años había pasado rumiando sobre sus textos, buscando una forma y un estilo que lo satisfacieran al punto de ponerlos a consideración de un público lector que venía, desde algún tiempo atrás, manifestando cambios de aguda significación.

En realidad, el país entero estaba cambiando.

Uruguay abre sus ojos al siglo XX inmerso en el proceso de consolidación institucional dirigido por José Batlle y Ordóñez. En sus dos presidencias (19031907, 1911-1915) se apaga definitivamente el úl timo movimiento insurreccional, epígono de las guerras civiles que, sistemáticas y cruentas, habían dibujado el perfil del siglo XIX uruguayo. Pero también se llevan adelante una serie de reformas - hoy podríamos otorgarles características social-demócratastendientes a regular las relaciones laborales e institucionales que habrían de marcar el desarrollo del Estado moderno y de hasta una idiosincracia nacional, sólo interrumpida momentáneamente por el golpe de estado del Dr. Gabriel Terra. 
Sin embargo, pocas fueron las reformas que la clase política heredera del legado batllista se atrevió a acometer más allá de las implementadas por su líder histórico. El estado de bienestar, una vez agotadas las ventajas de un país productor de materias primas agropecuarias en un escenario mundial marcado por sucesivas guerras, pronto comenzó a develar falencias apoyadas en los defectos estructurales de un sistema de producción poco conmovido por las medidas de principio de siglo. Podríamos decir entonces, apelando a un par de desvalorizados conceptos marxistas, que comenzaba a revelarse un severo desfasaje entre infra y superestructura: al concluir la primera mitad del siglo, el Uruguay pensaba (y vivía su cotidianeidad) como un país próspero, democrático, bonachón, y su economía lo iba acercando a un país ruinoso, autoritario, depredador.

Y en 1958, después de casi cien años de permanencia en el gobierno del Partido Colorado, el Partido Nacional, comandado por un oscuro líder cuyos pocos, breves y pueriles pensamientos lo acercaban demasiado al fascismo mussoliniano, gana las elecciones. Alli, claro que con la ubicuidad de todas las fijaciones temporales, daban comienzo las dos décadas que conmocionaron al país.

Hay que hacer una literatura uruguaya; hay que usar un lenguaje nuestro para decir cosas nuestras. ... La vida es tan rica en Nueva York como en la isla de Pascua cuando se tiene la sensibilidad que se necesita. ... Es necesario que nuestros literatos miren alrededor suyo y hablen de ellos y su experiencia. Que acepten la tarea de contarnos cómo es el alma de su ciudad. Es indudable que si lo hacen con talento, muy pronto Montevideo y sus pobladores se parecerán de manera asombrosa a lo que ellos escriban.

Estas tres frases pertenecen a sendos artículos aparecidos en 1939 en el semanario Marcha firmados por Periquito el Aguador, seudónimo bajo el que se escondía un escritor que, ese mismo año, daría a conocer su primer novela. Se trataba de Juan Carlos Onetti y su obra El pozo abriría, con la lentitud con que todas las cosas suceden en nuestro país, un nuevo rumbo en la literatura nacional.

Marcada a fuego por la corriente llamada "criollista" o "nativista", cuya producción se hallaba en franco agotamiento, nuestra literatura no parecía en ese entonces preparada para un sacudón de tal magnitud, que la obligara no sólo a revisar los lineamientos generales que le habían dado forma, sino también a los nombres de algunos popes que se movian en el escenario cultural con la parsimonia de un elefante. Emir Rodríguez Monegal subraya para ese entonces la sobrevida legítima de dos escritores, cuyas virtudes siguen siendo hoy de absoluta vigencia: Juan José Morosoli y Francisco Espínola.

Pero en ellos, la aproximación a lo urbano llegaba sólo hasta el pueblo o el suburbio de la ciudad del interior: sus palabras aún no cruzaban hasta las "luces del centro", las mismas que habían comenzado a deslumbrar, con indisimulada 
fascinación, a los letristas de tango. La ciudad, territorio aún inexplorado y ya centro de las transformaciones políticas (el gaucho, la montonera, las guerras civiles ocurridas en el medio rural entraban al reino de la nostalgia, de la imaginería tradicionalista), no tenía, a diferencia de otras literaturas, quien le escribiera. Y ese sería uno de los puntos del debate de un nuevo grupo de creadores que años más tarde se conocería como la "generación del “ 45 ”.

"Montevideo y sus pobladores", tal como lo señalaba Onetti, deberán esperar sin embargo veinte años para poder reconocerse en los héroes de una ficción que recién comenzará a tomar cuerpo en algunos textos de alrededor de 1960. Es justamente en esa década, y luego del largo impasse ocupado por tres nuevas novelas del autor de El pozo (entre las que se cuenta La vida breve, el título mayor de nuestra narrativa), que comenzará a registrarse una avalancha abrumadora, en la que habrán de destacarse dos nombres que harán del mundo urbano y sus agonistas el centro de sus historias: Mario Benedetti y Carlos Martínez Moreno.

Durante el día de primavera había llovido; pero al atardecer escamp6, si bien duraba aún en la atmósfera una humedad densa y caliente. En las calles mojadas se reflejaban borrosamente las luces, achatadas y confusas, y ni el aire ni el reflejo estaban lavados. Por la avenida 18 de julio, la gente llenaba las aceras y desbordaba sobre la misma calzada, desde que los escrutinios habian empezado a indicar, sin duda alguna, la derrota del gobierno y el triunfo del Partido Nacional. Era el 30 de noviembre de 1958 y tambien en Montevideo ganaban los blancos. Aislados por la lluvia del día y por los malos caminos, algunos circuitos electorales demoraban aún sus informaciones, pero no había que esperar más para saber que el Partido Colorado habia sido batido en todo el pars.

Este párrafo abre la primer novela de Martínez Moreno. El paredón, que resultará finalista del Concurso Biblioteca Breve de Seix Barral, es publicada por la editorial española en 1963 y provocó las más diversas reacciones en el ambiente cultural montevideano. Con ella, CMM daría comienzo a una saga que culminaría en 1981 con El color que el infierno me escondiera, en la que aborda justamente el fin de un proceso político que tendría como protagonistas la agudización de la crisis económica, el surgimiento de la guerrilla urbana y la posterior irrupción de los militares en la escena política.

Antes de $E l$ paredón, CMM había publicado dos libros de cuentos: el ya señaladoLos días por vivir y Cordelia. Hasta entonces, sus relatos denunciaban en primera instancia una obsesiva prolijidad formal, una adjetivación abigarrada, barroca, y una suerte de compulsiva necesidad por la cita intelectual, "culturosa" (si en francés mejor), y en segundo término una indisimulada tensión por subvertir los breves límites del género.

Rodríguez Monegal, en su Literatura uruguaya del medio siglo, anotaría con referencia a estos libros que "Más que la anécdota interesa a Martínez Moreno [...] la situación existencial en que aparecen enclavadas sus creaturas. 
Son las suyas, sobre todo, narraciones de personaje, exploraciones de almas, búsqueda del significado plural y contradictorio, siempre contrapuntístico de la existencia humana". Estas consideraciones estaban también dedicadas a Los aborigenes, tercer volumen de cuentos que apareciera en 1964, pero en el que, y junto a $E l$ paredón, comenzaba a evidenciarse un proceso que el propio Rodríguez Monegal definía de esta manera: "A medida que Martínez Moreno ha ido madurando como narrador, el rigor estilístico ha empezado a parecer sólo un medio de comunicación más que un fin en sí mismon.

En $E l$ paredón, el contrapunto involucra, ya a la distancia, más que a un espacio interior de su personaje, a dos realidades totalmente distintas: por un lado, a la lentitud con que algunos cambios comienzan a verificarse en la sociedad uruguaya (y a la monotonía y desaprensión con que estos son abordados por la intelectualidad montevideana) $\mathrm{y}$, por otro, a la incontenible dinámica con que se viven los primeros pasos de la recién triunfante Revolución Cubana.

Julio Calodoro, el protagonista de la novela, es un periodista cuarentón que testifica, dialogando con su padre (batllista sanguíneo), el triunfo nacionalista, el alborozo de la gente en la calle y el más que seguro engaño que esta habrá de sufrir, inserta en un sistema que, por más que en ese momento se atreva a una sustitución de fracciones, ha hecho de la inmovilidad su registro sine qua non. Frente a elloy pocos meses después (enero/febrero del '59), Calodoro presenciará en Cuba los comienzos de un proceso más que vertiginoso: el pueblo siguiendo paso a paso cada una de las decisiones de la Revolución en el poder y, en particular, los primeros juicios llevados adelante contra los esbirros militares de Batista.

Varios, más que los señalados, son los planos en los que la novela se desarrolla. Esa suerte de golpe de gracia sobre la identidad política de su padre hace que Calodoro revise su propia infancia y que más tarde, sobre el final del texto y a su regreso de Cuba, deba enfrentarse con la anunciada muerte de su progenitor. En Montevideo, el protagonista tiene una amante con la que ha establecido un vínculo monótono y reasegurador; en Cuba, habrá de conocer a una mujer con la que tendrá un breve, fogoso y "conmovedor" romance que le llevará a replantearse su actitud frente al amor y la pareja (esta relación, melodramática, poco verosímil, atribuible a las compulsivas veleidades de un "uruguayan lover", amenaza desbaratar los aciertos parciales del texto). Buena parte de la propia generación del $\mathbf{4 5}$ frecuenta tertulias que Calodoro parece padecer y disfrutar al mismo tiempo, mientras se suceden las opiniones casi ensayísticas de más de un intelectual que, si bien Martínez Moreno rebautiza y deforma, es factible identificar (Arturo Despouey, Denis Molina, Homero Alsina Thevenet, Hugo Alfaro, Mario Arregui ...), los que luego serán también comparados con un grupo de artistas cubanos, acaso más frívolos, más amorales pero, a deducir por las intenciones del autor, pertenecientes todos a una misma especie universal.

Seguramente, CMM no previó, por mayor que fuera su lucidez, lo profético que habría de resultar El paredón, tanto para la vida del país y de todo el continente como para su propia obra novelística. Porque de esos contrapuntos 
y enfrentamientos de una realidad y de un ser interno y, por qué no, también social, habrían de surgir los sucesos de dos décadas de derrumbe y violencia, que el propio autor haría materia argumental, cada vez más tensa, cada vez más dramática, del grueso de sus futuros libros.

En 1966, CMM publica dos novelas. Una de ellas, de impecable factura, aborda el irresistible descenso del patriciado uruguayo (Con las primeras luces). La otra, se detiene en la desolación de un individuo que un buen día se entera de la muerte de su amante y del marido de ésta (La otra mitad).

La otra mitad es un ejercicio introspectivo, tan arrogante como engorroso, donde es difícil encontrar un sustantivo en soledad o acompañado de menos de dos o tres adjetivos, que relata en primera persona las vicisitudes de una relación adúltera con fin abrupto. El protagonista-narrador (también cuarentón, esta vez profesor de literatura) se enfrenta en el comienzo del libro y de buenas a primeras al asesinato de su amante a manos del maridoy al inmediato suicidio de éste, en un suceso que parece haber necesitado del mutuo acuerdo de ambos y del desconocimiento de sus motivos por parte del narrador.

Pero sin duda CMM no fue un escritor feliz a la hora de las relaciones amorosas. Durante las 340 páginas de la novela, en las que se parafrasea el trágico fin de Delmira Agustini, el protagonista se aboca a investigar y revisar en su memoria la posible causa del incidente fatal sin llegar a ningún resultado. La novela pudo haber sido un thriller, un texto de intenciones eróticas (tuvo, no obstante, problemas con la censura española de su entonces y no pudo ser publicada en Seix Barral) o una aguda denuncia de la moralina del Montevideo de los '60, pero no fue más que un tedioso juego de pesadumbre intelectual, el que roza muchas veces lo llanamente cursi, tal como lo corroboraría la lectura de más de un párrafo como el siguiente: "De noche, vacuos y castos, verla volver del baño en camisón, haberla escuchado enjuagarse la boca, sentir el roce de su pie en las chinelas. ¿Qué bueno!".

Con las primeras luces es, en cambio, uno de los testimonios más lujosamente narrados acerca de la lenta agonía de una clase que había establecido su poderío económico y social al término de la llamada Guerra Grande, a mediados del siglo XIX. Después de una fiesta en una de las viejas casa-quintas montevideanas pertenecientes a un patriciado en absoluta decadencia, un hombre borracho se acuesta a dormir en un banco. El dueño de casa, primo suyo, cierra el portón de la estancia y se retira a su habitación. Cuando aquél se despierta, en plena madrugada, intenta saltar la verja, se perfora una ingle, se arrastra hasta la puerta de la mansión y, sin poder llamar ni hacer movimiento alguno, agoniza hasta el amanecer.

Pero esa agonía, un largo sendero de rememoraciones, le llevará a revisar su infancia y adolescencia, un pasado familiar cargado de íconos y mitos mitad históricos, mitad íntimos, y el moroso declive de una tradición aristocrática por el que también han caído definitivamente sus referencias personales y el resto de un estamento, suplantado rápidamente en los ' 60 por una clase vinculada a los grupos financieros y a los intereses multinacionales. 
Aquí aparecen nuevamente los conflictos vínculados a los dos partidos tradicionales y acaso a dos formas de vida contrapuestas en un pasado cada vez más lejano ("colorados y ateos", más proclives a la metropolización y a la influencia británica versus nacionalistas católicos, memoriosos de un pasado tocado por el gusto francés, por un orden más despiadado e inherente a todas las cosas). Esa derrota clasista, que también se vive como metáfora de la soledad familiar en el relato de un epígono, es abordada magistralmente por CMM: su barroquismo verbal se ajusta como parte propia del escenario que describe; el espesor de sus personajes, su opacidad, su melancolía, coinciden hasta la exactitud con el derrumbe de que ellos son partícipes; y el tratamiento de los tiempos narrativos, con sus permanentes alternancias de pasado y presente, no deja espacio a fatuidad alguna.

La dispersión de su gente -escribe CMM de Eugenio, el agonizante-no se había producido en el espacio, sino en el tiempo: Tía Rosina muerta repentinamente mientras dormía [...]; Tía Herminia muerta poco después, al cabo de una decadencia graduada, de enfermedad cardíaca; Roberto solo en el caserón, resistiendo la idea de que alguien pudiera acompañarle; su propia madre (Tía Elisa, en el lenguaje de la quinta) viviendo vegetativamente ....

Con Los prados de la conciencia (cuentos, 1968) y las novelas Coca (1970) y Tierra en la boca (1974), la anécdota parece igualar definitivamente a la reflexión existencial, no en su detrimento ni en el de su riguroso abordaje estilístico que, en buena medida, había hecho perder tensión narrativa a sus títulos anteriores. La aventura irrumpe en la escritura de CMM, hasta entonces obsedida por un extenso monólogo interior que quizás había dado comienzo en los ya lejanos primeros cuentos de su juventud.

Coca narra la historia de unos improvisados $-\mathrm{y}$, por momentos esperpénticos - traficantes de cocaína en un circuito cuyos escenarios son La Paz, Buenos Aires y Montevideo. Un oficial del ejército boliviano, herido y lisiado en un enfrentamiento en la revuelta minera de 1952 -la Revolución Nacionalista liderada por Paz Estensoro, evocada ya en El paredón- que cumple una misión diplomática en Buenos Aires, luego de un frustrado matrimonio con una mujer perteneciente a la aristocracia de su país; una francesa cuyo signo de identidad es la memoria de su adolescencia a finales de la Segunda Guerra Mundial y un belga ex-combatiente fascista, forman un triángulo en principio sentimental, que termina convirtiéndose en una suerte de vínculo delictivo que los llevará a intentar una operación de tráfico de drogas por el que terminarán detenidos en Montevideo. La novela, narrada desde diferentes puntos de vista dirigidos a un abogado a cargo del caso, revela casi por primera vez una intensidad incidental sostenida a lo largo de sus 200 páginas, y debajo de la cual se nos muestra un mundo marcado por la soledad y la corrupción: la diplomacia y algunas zonas de la política y los ejércitos del Cono Sur son puestos al desnudo.

Otro mundo, otras voces, otros ámbitos habrán de ocupar la siguiente novela de CMM, Tierra en la boca. En ella, dos rateros de baja categoría planean 
un simple robo a una carnicería, sin calcular ni estar preparados, para que el mismo termine en el asesinato de un viejo sereno que los descubre casualmente. De allí en más, la novela narra el interminable periplo de sus fugas, acompañados respectivamente por sus mujeres.

Pero Tierra en la boca marca también en el estilo del autor la irrupción de las múltiples subversiones, gramaticales y sintácticas, que el llamado boom latinoamericano ha provocado para ese entonces en las letras del continente. No es, sin embargo, afortunado el recorrido de CMM por este camino de digresiones: su inteligencia, la casi erudición de ese yo auxiliar narrador que lo acompañó a lo largo de toda su obra, se transparenta demasiado en un lenguaje que intenta parafrasear las características del idioma del bajo, de los suburbios, del cantegril. Y es esa misma inteligencia la que también socava la verosimilitud del monólogo del lumpen, su miedo convertido en remordimiento, su remordimiento convertido en culpa, su culpa en un filosofar casi presuntuoso si lo comparamos con sus referencias personales.

Noobstante, una de las intenciones de la novela parece cumplirse cabalmente, tal como fue señalado por Mario Benedetti en su Literatura uruguaya siglo XX:

la objetividad de la obra sirve para enjuiciar in directamente a este sistema, que si bien no es todavía (en la novela) la aberrante dictadura, ya lleva en sí mismo su pretexto y su germen. Tierra en la boca testimonia un derrumbe, y en ese sentido adicional, extraliterario, también constituye un aporte invalorable a la interpretación social de un período, particularmente crítico, del Uruguay contemporáneo.

Pero esas múltiples realidades que toda su obra se encargó de evidenciar e interpretar, esa sucesión de tribulaciones y rupturas que comenzaron a envolver al país en los '60, no lo podían haber encontrado como un testigo neutro, aséptico, falto de compromiso. Es así que, con la irrupción de la guerrilla tupamara, con la intensificación de la violencia "oficial", con la instauración de los tribunales militares y el posterior Golpe de Estado de 1973, se irán sumando sus defensas de presos políticos. A comienzos de la dictadura asume, junto al Dr. José Korzeniak, la defensa del Gral. Líber Seregni, líder del Frente Amplio, pero permanentemente asediado por los militares en el poder, decide al fin abandonar el país. En 1976 parte para España, primera etapa de su exilio, de donde se marchará tiempo después rumbo a México, país que lo cobijó hasta su muerte y donde escribiría y daría a conocer su última novela.

El color que el infierno me escondiera no es sólo la mejor novela sobre los sucesos políticos ocurridos en Uruguay desde mediados de los ' 60 hasta fines de los '70 sino la mejor novela de toda la generación del ' $45 \mathrm{y}$, claro está, de la producción de CMM.

Fracturada, estallante, implosiva y explosiva, tal como la propia realidad que aborda, la ruptura aparente de la unidad de acción define la forma de $E l$ color .... Sus veintidós capítulos enfocan casos diferentes (CMM llegó a publicar 
dos de ellos como relatos unitarios los que figuran en Animal de palabras), pequeñas realidades de un mismo infierno (es un verso de Dante el que da nombre a la novela; son versos de Dante los que abren cada uno de ellos), instancias parciales de un período dramático, asolador, feroz. Es así que por sus páginas desfilan episodios claves de un tiempo vertiginoso y despiadado: Dan Mitrione instruyendo métodos de tortura a policías y militares uruguayos; Dan Mitrione secuestrado y ajusticiado por la guerrilla tupamara, los secuestros de Ulyses Pereira Reverbel y de Pellegrini Giampietro la tortura en los cuarteles; el asesinato del peón Pascasio Báez; la desaparición del maestro Julio Castro y aún otros casos de elocuente brutalidad.

La escritora Mercedes Rein ha señalado que la novela "recrea poéticamente el sentido y el sinsentido de ese infierno en la tierra con la objetividad de un hombre extremadamente inteligente y el fervor de un agonista que sublima, mediante la palabra, el horror de un mundoque parece estallar dentro de él pero que es dominado por la maestría de un gran escritor en la plenitud de sus posibilidades".

El texto tiene momentos de absoluta brillantez, comola suerte de monólogo de Dan Mitrione, reflexionando sobre su soledad una vez que comprende que está realizando su último viaje, o como el debate moral de un integrante de la guerrilla frente al asesinato de un peón de campo que descubre, sin querer, un aguantadero en una estancia. El libro no oficia en ningún momento a modo de alegato parcial frente a los sucesos, sino que resulta un testimonio apasionado pero nunca panfletario, equilibrio sólo posible en la voluntad esencialmente lúcida de su creador.

Elcolorqueel infierno meescondiera ganó en 1981 el Concurso Internacional Proceso-Nueva Imagen sobre "El militarismo en América Latina", con un jurado integrado entre otros por Julio Cortázar, Gabriel García Márquez, Ariel Dorfman y Carlos Quijano, y en el momento de su publicación CMM fue blanco de diversas acusaciones (uso de datos obtenidos por su defensa directa de algunos casos, exposición a represalias a guerrilleros aún detenidos) y de una ya célebre cachetada que un exiliado tupamaro le propinó en México. Pero todo eso, sin duda, ya ha pasado a formar parte del lado mezquino de la historia.

Después de todo -reflexionaba Carlos Martínez Moreno/Julio Calodoro, en El paredón- la ciudad en que se vive es el único sitio en que uno se resignaría a enfermarse, a llamarse a un silencio definitivo, a ser olvidado de todos, a morir. Y esa ciudad, entonces, era "Esta Montevideo, madre cruel" de los versos de Líber Falco evocados por el narrador, el mismo que escribiria, veinte años después, lo siguiente:

De un libro debería uno despedirse como de una persona. Pero nunca lo hacemos: tanto se ha viciado nuestra relación de criatura con él.

Y el libro se convierte entonces en una cosecha de difuntos o vivientes, fuera de nuestro alcance; ni siquiera nos sentimos llamados a ser solidarios con él, a morir en las páginas donde su gente muere, a haber odiado $o$ amado cuando ella lo haya hecho (El color ...). 
"Este libro, madre cruel", parecería pues la previsible metáfora. En sus libros y en su ciudad habitó esa "cosecha de difuntos o vivientes", hombres y mujeres henchidos del grosor de lo perentorio y de lo esencial, de lo grávido y de lo eterno, de lo nostálgico y de lo profético.

Y es que, después de haber leído y revisado toda su obra, y de estar acercándome a los primeros días de 1986 y de saber nuevamente de la muerte de Martínez Moreno, se me ocurre que por primera vez se vislumbra con total nitidez la simultaneidad de la muerte de todos los héroes de su ficción, de la misma forma en que también murio, hace ya mucho tiempo, el pars que todos ellos habitaron.

Y siento también que esa coincidencia se dimensiona hasta lo exacto en tanto, muy lejos de esta "ciudad en que se vive", la muerte del escritor contradijo la sentencia del personaje.

\section{Obras de Carlos Martínez Moreno}

Los dias por vivir (cuentos, Montevideo: Asir), 1960.

Cordelia (cuentos, Montevideo: Alfa, 1961).

El paredón (novela, Barcelona: Seix Barral, 1963).

Los aborígenes (cuentos, Montevideo: Alfa, 1964).

Con las primeras luces (novela, Barcelona: Seix Barral, 1966).

La otra mitad (novela, México: Joaquín Mortiz, 1966).

La sirena y otros relatos (recopilación de cuentos, Capítulo Oriental, 1968).

Los prados de la conciencia (cuentos, Montevideo: Alfa, 1968).

Coca (novela, Caracas: Monte Avila, 1970).

De vida o muerte (recopilación de cuentos, Buenos Aires: Siglo XXI, 1971).

Tierra en la boca (novela, Buenos Aires: Losada, 1974 y Montevideo: Arca/ Monte Sexto, 1990).

El color que el infierno me escondiera (novela, México: Nueva Imagen, 1981 y Montevideo: Monte Sexto, 1986).

Animal de palabras (cuentos, edición póstuma, Montevideo: Arca, 1987). 
